\title{
Tratamiento lexicográfico de los compuestos léxicos y cultos en los diccionarios del español ${ }^{*}$
}

\author{
Lexicographical handling of lexical and neoclassical \\ compounds in Spanish dictionaries
}

Cristina Buenafuentes de la Mata

Universidad Autónoma de Barcelona

RESUMEN: Este trabajo examina la práctica lexicográfica en el terreno de la formación de palabras, centrándose, especialmente, en la composición léxica y culta desde los primeros repertorios léxicos hasta la actualidad. Así pues, el propósito de esta investigación es efectuar una propuesta para el tratamiento de este tipo de formaciones en los diccionarios haciendo hincapié en cómo deberían resolverse desde el punto de vista lexicográfico los distintos inconvenientes que plantean los compuestos en el seno de la teoría morfológica.

Palabras clave: formación de palabras, derivación, composición, composición léxica, composición culta, lexicografía.

ABSTRACT: In the present study we will examine the lexicographical practises employed in word formation; in particular, the lexical and neoclassical compounds found in early text up until the present. Thus, our purpose is to propose a new way of handling these constructions as part of their dictionary entry by emphasizing how to lexicographically resolve the problems caused by compound structures.

Keywords: word formation, derivation, compounding, lexical compounding, neoclassical compounding, lexicography.

* La presente investigación ha sido financiada con una ayuda del MEC y FEDER ( $\mathrm{n}^{\mathrm{o}}$ de ref. FFI2011-29440-C03-01 y FFI2011-24183) y de la CIRIT del Comissionat per Universitats i Recerca de la Generalitat de Catalunya ( ${ }^{\circ}$ de ref. 2009SGR 1067). 
La morfología, pese a ser una de las disciplinas esenciales de la gramática, todavía presenta algunas lagunas, sobre todo en cuanto a la descripción y definición de algunos de sus componentes. Como es bien sabido, conceptos básicos en la teoría morfológica como morfema o palabra no han tenido una definición del todo consensuada en la descripción lingüística y "la definición de la palabra compuesta plantea los mismos problemas que la definición de la palabra" (González Ollé y Casado Velarde, 1991: 103).

Las dificultades en la delimitación de la composición se centran, sobre todo, en su distinción con respecto a determinados casos de derivación ${ }^{1}$. Estos problemas se trasladan al ámbito lexicográfico en el momento en que deben caracterizarse y clasificarse las unidades que constituyen el acervo léxico de una lengua. Así, el tratamiento lexicográfico de la composición ha sido bastante disperso y heterogéneo en la historia de la lexicografía, lo que muestra la problemática que subyace tras "las arenas movedizas de las palabras compuestas" (Lorenzo, 1995: 35). Como señala González Pérez (2002: 109), “los lexicógrafos han de tomar decisiones terminológicas constantemente $\mathrm{y}$, muchas veces, en terrenos conflictivos y no bien delimitados".

En este sentido, no existe ningún estudio que analice la aparición y tratamiento de la composición ${ }^{2}$ en los diccionarios monolingües del español ${ }^{3}$, haciendo hincapié en cómo se resuelven desde el punto de vista lexicográfico los distintos inconvenientes que plantean los compuestos en la teoría morfológica. Por ello, el propósito de este trabajo es examinar la práctica lexicográfica ${ }^{4}$ en el ámbito de la formación de palabras centrándonos, sobre todo, en la composición léxica y culta, con el objetivo final de efectuar una serie de propuestas para el tratamiento de este tipo de creaciones en cualquier diccionario.

\section{TRATAMIENTO LEXICOGRÁFICO DE LA COMPOSICIÓN PROPIA O LÉXICA}

La composición léxica es el tipo de proceso compositivo prototípico. Así, cuando se quiere definir la composición como mecanismo morfológico de for-

\footnotetext{
${ }^{1}$ También resulta problemática la diferenciación entre la composición sintagmática y las locuciones. Para un tratamiento exhaustivo de esta cuestión, véase Buenafuentes de la Mata (2010).

${ }^{2}$ Sí que existen numerosos trabajos que tratan, desde el punto de vista lexicográfico, fenómenos afines a la composición como, por ejemplo, la derivación o las unidades fraseológicas (colocaciones, locuciones, refranes, etc.). Sirvan como ejemplo, para el primer caso, los trabajos de Pena (1994-1995 y 2002) o Martín García (2000); para el segundo, el libro misceláneo de Alonso Ramos (2006).

${ }^{3}$ Cabe tener presente que se han elaborado algunos trabajos en otras lenguas como el inglés o el francés como los de Corbin y Corbin (1989) o Caluwe y Taeldeman (2003).

${ }^{4}$ En el presente estudio, se han seleccionado los compendios lexicográficos (tanto históricos como actuales) que, a nuestro juicio, muestran algún aspecto significativo respecto a la incorporación de la morfología derivativa en la práctica lexicográfica.
} 
mación de palabras, siempre se acude a esta clase compositiva, ya que se considera un ejemplo claro de la creación de nuevas voces a partir de este procedimiento. Según Alemany Bolufer (1920: 262-263):

Dos condiciones se requieren para la formación del vocablo compuesto, una lógica y otra gráfica. En virtud de la primera se funden en la mente dos ideas, para designar una nueva; y en virtud de la segunda, se juntan en la escritura las voces que designan dichas ideas. Así noroeste no designa el norte y el oeste, sino el punto intermedio entre aquellos dos, y que por no tener vocablo propio con que expresarlo, nos valemos de la fusión en una de las voces que sirven para la denominación de aquéllos.

De hecho, la gramática tradicional la denominó composición propia o perfecta, en contraposición a la imperfecta que es la de tipo sintagmático (véase Buenafuentes de la Mata, 2010). De esta manera, la composición léxica se caracteriza por ser el resultado de la unión gráfica, morfológica y semántica de dos bases, ambas de origen patrimonial. Ejemplos de ello son las palabras $c a-$ rricoche 'carro cubierto cuya caja era como la de un coche', formada por los sustantivos carro y coche; lavavajillas 'detergente líquido que se utiliza para lavar la vajilla', constituida por el verbo lavar y el sustantivo vajilla; o sordomudo 'privado por sordera nativa de la facultad de hablar' compuesta por los adjetivos sordo y mudo.

$\mathrm{Su}$ "prototipicidad" o "perfección" hace pensar que su tratamiento lexicográfico no plantea problemas y que los diccionarios actúan de la misma manera a la hora de incluir estas palabras complejas en su estructura. Si bien este tipo de composición es el que acarrea menores dificultades desde el punto de vista lexicográfico, se observan tres cuestiones problemáticas en la teoría morfológica que se han tenido que resolver, con mayor o menor acierto, en las obras lexicográficas analizadas: la distinción entre prefijación y composición, la predictibilidad de los procesos de formación de palabras $\mathrm{y}$, finalmente, la naturaleza de los compuestos con guion (coche-cama, árabe-israelí, físico-químico).

\subsection{Límites entre prefijación y composición}

Una de las cuestiones controvertidas, sobre todo en los primeros compendios léxicos, es la consideración de la prefijación como una clase compositiva. Como señala Cabré (2002), la distinción entre la composición y determinados casos de prefijación es uno de los grandes problemas dentro de la teoría morfológica. Esta dificultad radica, en parte, en la propia definición de compuesto basada en la independencia de los miembros que intervienen en la for- 
mación. Muchos de los elementos que se anteponen a una base suelen ser unidades preposicionales o adverbiales, lo que les confiere una autonomía que las adecua a la definición de la composición y no a la de la derivación. Según esta concepción, palabras como sobrevolar o contrarrestar son consideradas compuestas por prefijación ${ }^{5}$.

Así, la inclusión de la prefijación como un subtipo dentro de la composición va a ser una constante en los primeros diccionarios ${ }^{6}$. En el Tesoro de la lengua castellana de Covarrubias, pese a ser poco frecuente, se pueden encontrar muestras de la pertenencia de las preposiciones que intervienen en la creación de palabras a los mecanismos compositivos:

DES. Responde a la preposición latina dis. Hállase tan sólo en composición; algunas vezes nota negación, como descompuesto no compuesto, desdichado sin dicha. (Covarrubias, 1611: s. v. des).

RE, esta particula en composición, acrecienta la sinificación, como lleno, relleno. (Covarrubias, 1611: s. v. re).

Esta es la misma actuación que se puede observar también en el primer diccionario académico, según indica Torres Martínez (2006: 1850-1851):

[...] el Diccionario de autoridades emplea la misma terminología y paráfrasis para definir tanto a las voces que actualmente consideramos derivadas por prefijación -mediante combinación de un prefijo, morfema ligado, antepuesto al lexema - como a las formadas por composición - mediante la unión de dos lexemas, palabras independientes-.

Así ocurre con las siguientes preposiciones de las que el Diccionario de autoridades señala su uso en la composición de palabras ${ }^{7}$ :

RE. Particula que en composicion, regularmente aumenta y reduplica la significación, anssi en nombres, como en verbos, como de Lleno Relleno, de Clamar Reclamar. (Aut.: s. v. re).

SOBRE. Sirve freqüentemente a la composicion de nombres, y de verbos, correspondiendo al Super Latino; y, o aumenta la significacion, o le añade la suya al nombre, o verbo que compone: como Sobrecoger, sobreponer, sobrecarga. (Aut.: s. v. sobre).

\footnotetext{
5 Esta consideración también se refleja en las gramáticas históricas y tratados morfológicos tradicionales como los de Darmesteter (1874), Hanssen (1913) o Alemany Bolufer (1920). La primera gramática que señala que composición y prefijación son mecanismos distintos es la de Menéndez Pidal (1940), aunque en ocasiones la diferenciación no queda del todo clara.

6 También es habitual hallar la parasíntesis dentro de la composición.

${ }^{7}$ En este aspecto, este diccionario carece de sistematicidad ya que recoge preposiciones (aunque no todas) y también formas que no coinciden con una preposición en español como, por ejemplo, extra o soto, tal y como se analiza en Torres Martínez (2006: 1852-1853).
} 
De hecho, al definir el término preposición el diccionario indica que "Sirven tambien las preposiciones para la composicion o formacion de algunos verbos: como Anteponer, Predecir, Proclamar, \&c.".

Por su parte, el diccionario de Terreros es el primer repertorio que comprende el término composición entre sus lemas, pero su concepción sigue en la misma línea que sus predecesores, aunque se sustituya el término "preposición" por el de "partícula":

COMPOSICION, en la Gramatica, la acción, o junta de alguna partícula a esta, o la otra voz, aumentando, disminuyendo, o inmutando, por lo comun, la significacion. (Terreros, 1786: s. v. composicion).

En este sentido, resulta interesante la información que aporta sobre la partícula re:

RE, es tambien una partícula que aunque sola no significa cosa alguna, entra en la composición de multitud de palabras, tanto de nombres como de verbos [...] y familiar y jocosamente apenas habrá voz en Cast. a que no se pueda aplicar [...]. (Terreros, 1786: s. v. re).

Esto indica claramente que los primeros compendios léxicos tenían una visión etimológica de estas "partículas" ya que, pese a no tener significado en español, al funcionar independientemente en la lengua latina, se les confería el estatuto de elementos autónomos y, por tanto, se consideraban formadoras de compuestos.

La misma concepción de la composición no se manifiesta explícitamente en el diccionario académico hasta la edición de 1884, como se observa en la definición que ofrece del término y que se repite hasta la vigésima primera edición ${ }^{8}$ :

COMPOSICION. Gram. Procedimiento por el cual se forman vocablos agregando a uno simple una o más preposiciones o partículas u otro vocablo íntegro o modificado por eufonía; v. gr.: anteponer, reconvenir, hincapié, cejijunto. (DRAE, 1884: s. v. composicion).

Como se puede observar, la composición se sigue considerando un proceso de creación de palabras que abarca también la prefijación y, por ello, palabras prefijadas como anteponer o reconvenir se sitúan al mismo nivel que compuestos prototípicos como hincapié o cejijunto.

Se podría pensar que la aparición del término prefijo o afijo dentro de los repertorios lexicográficos supondría un cambio en el concepto de composición.

8 De hecho, varios diccionarios, como el de Zerolo (1895) o el de Rodríguez Navas y Carrasco (1918) reproducen exactamente la definición académica. 
Sin embargo, la idea que se observa en los distintos diccionarios que definen esos vocablos redunda en la consideración de la prefijación como un subtipo de composición:

PREFIJO, JA. [...] m. La partícula que puesta delante de una voz, modifica o hace variar su significado, como se ve en inútil respecto de útil. ${ }^{9}$ (Salvá, 1846: s. v. prefijo, a).

PREFIJO, JA. [...] adj. Gram. Preposicion, partícula o voz que se antepone a un vocablo simple para convertirlo en compuesto o modificar su significado. (DRAE, 1869: s. v. prefijo, a).

Prefijo, s., adj. y part. Gram. Elemento compositivo de palabras; partícula prepositiva que modifica la significación de las palabras a que se antepone como des, pre, mal, que antepuestos al verbo decir forman los verbos desdecir, predecir, maldecir. (Rodríguez Navas, 1918: s. v. prefijo).

Es a partir de la edición del diccionario académico de 1884 que se añade en la definición de prefijo el término afijo (que, por otro lado, ya se había definido, por primera vez en una obra lexicográfica, en el $D R A E$ de 1817). Sin embargo, este viene a sustituir, en sus primeras apariciones, a lo que antes se denominaba "partícula", "preposición" o "elemento compositivo", por lo que la visión de la prefijación como parte de la composición se mantiene inamovible:

PREFIJO, JA. [...] adj. Gram. Dícese del afijo que va antepuesto; como en DESconfiar, REponer, MONDAdientes. (DRAE, 1884: s. v. prefijo, ja $)^{10}$.

De hecho, en el diccionario de Alemany Bolufer (1917: s. v. composición) se constata claramente la pertenencia del término afijo (y, por consiguiente, la prefijación) a la composición de palabras:

COMPOSICIÓN. Gram. Procedimiento por el cual se forman vocablos agregando a uno simple algún afijo.

Incluso, el propio autor, en su tratado sobre la formación de palabras, señala respecto a los prefijos que:

Damos el nombre de prefijo a las preposiciones, y también a los vocablos o partículas que no teniendo existencia independiente en la lengua, se emplean antepuestas a un substantivo, adjetivo o verbo, para formar, ya compuestos puros, ya parasintéticos. (Alemany Bolufer, 1920: 423).

El único cambio que experimenta la definición de prefijo desde la edición del diccionario académico de 1914 es la supresión del último ejemplo que se

\footnotetext{
${ }^{9}$ La misma definición se ofrece en Gaspar y Roig (1853) o en Domínguez (1846-1847).

${ }^{10}$ Esta misma consideración es la que se sigue en el DRAE (1899), Zerolo (1895) y Toro y Gómez (1901).
} 
ofrece, lo que puede llevar a la conclusión de que se empezaba a vislumbrar que el estatuto de mondadientes no estaba al mismo nivel que el de voces como desconfiar o reponer.

Como se puede observar, los repertorios lexicográficos analizados no hacen más que reflejar la controversia existente en la teoría morfológica en cuanto a la naturaleza de la prefijación y la composición, cuestión que se extiende hasta bien entrado el siglo XX. De hecho, aún el Esbozo de la Real Academia en 1973 sigue considerando la prefijación dentro de los mecanismos compositivos: "Ateniéndonos al método tradicional, consideramos las palabras en que entran tanto preposiciones propias: contra-hacer, ante-cámara, sin-razón como impropias: hiper-democracia como palabras compuestas" (Real Academia Española, 1973: § 2.1.4e). Según lo expuesto, por tanto, la consideración de la composición como un proceso distinto de la prefijación es algo bastante moderno. En la actualidad, la teoría morfológica considera que la prefijación no debe considerarse un tipo compositivo, pues sus propiedades semánticas y formales la acercan al comportamiento afijal y no al de la composición de palabras. Por tanto, la definición de los mecanismos compositivos basada únicamente en la autonomía de sus miembros constitutivos ha sido superada y, para distinguir mejor ambos procedimientos, cabe atender además a sus rasgos como formador de palabras (véase Lázaro Mora, 1986: 223-224). Así se manifiesta en los diccionarios actuales como el Diccionario Salamanca de la lengua española (DSLE), el Diccionario del español actual (DEA), el Diccionario de la lengua española de la Real Academia (DRAE, 2001), el Diccionario de uso del español de América y España (DUEAE) y el Diccionario de uso del español (DUE):

GRAM. Procedimiento de formación de nuevas palabras a partir de la unión de dos o más elementos léxicos capaces de funcionar autónomamente en la lengua: "Guardiacivil" es una palabra creada por composición. (DSLE: s.v. composición).

(Ling.) Procedimiento de formación de palabras mediante la unión de otras palabras, o de raíces afijas, o de una palabra con una raíz afija o con un prefijo. (DEA: s.v. composición).

Gram. Procedimiento por el cual se forman palabras juntando dos vocablos con variación morfológica o sin ella; p. ej., cejijunto, lavavajillas. Se aplica también a las voces formadas con vocablos de otras lenguas, especialmente del latín y el griego; p. ej., neuralgia, videoconferencia. (DRAE, 2001: s.v. composición).

Procedimiento morfológico de formación de palabras mediante la unión de dos o más palabras que ya existen en la lengua. (DUEAE: s.v. composición).

Gram. Procedimiento de formación de palabras mediante la unión de dos o más elementos con valor independiente; se trata generalmente de nombres, verbos o adjetivos a los que se añaden, bien afijos o raíces cultas, bien otros nombres, verbos o adjetivos. (DUE: s.v. composición). 
Como se puede observar a partir de estos ejemplos, existen pequeñas discrepancias en cuanto a la definición de composición que atañen, no al estatuto de la prefijación, sino más bien a la naturaleza de los elementos cultos que intervienen en la creación de palabras y que trataremos más adelante.

\subsection{Predictibilidad de los procesos de formación de palabras}

Como se ha señalado, otra de las cuestiones morfológicas a las que intenta responder el diccionario es la de la recursividad y transparencia de determinados procesos de creación de palabras.

A primera vista, los diccionarios no deberían recoger palabras, en nuestro caso, compuestos, cuya significación es transparente o composicional, es decir, cuando el significado de la formación se deduce a partir de los miembros que la constituyen. Esta es la intención de, por ejemplo, el Diccionario de autoridades, tal y como expone en su prólogo:

[...] ha formado el Diccionario, sujetandose a aquellos principios, y continuando despues debaxo de las reglas que la han parecido mas adequadas y convenientes, sin detenerse con demasiada reflexión en el origen y derivación de las voces: porque además de ser trabájo de poco fruto, sería penoso y desagradable a los Lectores, que regularmente buscan la propriedád del significado: y el origen ó la derivación, quando no es mui evidente y claro, quedaba siempre sujeto a varios conceptos, despues de ser desapacible su lección, y que ocasionaría un volumen fastidioso y dilatado. (Aut.: II).

Es decir, en el primer diccionario académico se priorizó el significado frente a la etimología o la derivación. De hecho, tal y como señala Alvar (2002), el espacio que ocupan las voces derivadas y compuestas en esta obra es bastante reducido, ya que "únicamente pusieron los diminutivos y aumentativos más utilizados, y con la autoridad de los escritores clásicos, además de las irregularidades y usos anómalos verbales [...]" (Alvar, 2002: 273) procedimiento que en la segunda edición se extendió a todas aquellas voces "fácilmente formables"11. Esto es debido, según la institución, a que "en la gramática se explica el modo cómo se forman todas estas especies de voces, y la modificación que causan en las primitivas, y a ella se debe acudir el que por ventura los ignore" (DRAE, 1832: I) ${ }^{12}$. Al ser tratadas en la gramática, no tiene sentido que figuren estas voces en el diccionario.

${ }^{11}$ De hecho, esta suele ser la práctica de otros diccionarios como los de Domínguez (18461847) o Zerolo (1895), ya que se valen de abreviaturas para dar cuenta de algunas cuestiones que afectan, sobre todo, a la derivación apreciativa, como los diminutivos (dim.) o aumentativos (aum.), al superlativo o a los participios irregulares.

${ }^{12}$ La misma consideración se halla en la edición de 1884. 
Pese a remitir a los tratados gramaticales para las particularidades en cuanto a la derivación y composición de voces, resulta curiosa la preocupación de la institución por los mecanismos de creación de palabras ya que, según señala Alvar (2002: 274), a partir de la edición de 1884, se añade un apéndice en el que se da cuenta de las reglas de formación de derivados (sobre todo, diminutivos, aumentativos y el superlativo) que se mantiene (con algunas modificaciones) hasta la edición del 2001. A pesar de contar con este anexo relativo a la derivación, no se dan indicaciones sobre el proceso regular de creación de compuestos en español, aunque es evidente que los diccionarios no incluyen (ni deben hacerlo) las palabras compuestas de significación composicional, tal y como señala Pena (1994-1995: 167):

Frente al caudal no finito de palabras posibles en una lengua según las RFP, está el diccionario que, como código de la norma (o, mejor dicho, como código de las palabras reales en sentido de documentadas), es necesariamente finito, por muy numeroso que sea y por muchas que sean las dificultades para registrar la totalidad.

Las voces complejas que en mayor número se ven "excluidas" por los diccionarios debido a la regularidad de su formación y a su transparencia semántica son los compuestos que agrupan un verbo y un nombre (lavavajillas, portabebés) y los que aúnan dos adjetivos que designan colores (verdiblanco, rojiblanco $)^{13}$.

En cuanto a los compuestos de verbo y nombre, los diccionarios casi siempre introducen formaciones con esta estructura cuyo significado es deducible, pese a lo que suele indicarse en los prólogos ${ }^{14}$. Además, la relación de palabras compuestas que figuran difiere de una obra a otra. Por ello, la Real Academia Española y la Asociación de Academias en su Nueva gramática de la lengua española (NGLE) señalan que

[...] la considerable productividad de algunas pautas de la morfología compositiva impide que los diccionarios registren todas las formaciones que permiten crear. [...] Así pues, no todos los diccionarios del español recogen los sustantivos limpiacristales, limpiametales, limpiasuelos, limpiapisos o limpiavidrios. Tales ausencias son esperables, ya que la productividad del es-

\footnotetext{
${ }^{13}$ Cabe señalar en relación a este tema que nos centramos exclusivamente en el significado que presentan estas voces, por lo que no tenemos en cuenta cuestiones de índole diatópica, diastrática o pragmática, siempre que estas no se expliciten en el propio diccionario. Es decir, somos conscientes de que algunos compuestos, pese a ser transparentes semánticamente, no pueden usarse en todos los contextos, sino que su empleo depende de factores externos, como la procedencia geográfica, el registro, etc.

14 "No dejan de sorprender hoy cuando observamos la cantidad de derivados regulares y formas paradigmáticas que hay en las macroestructuras de los diccionarios”, según señala Alvar (2002: 274).
} 
quema morfológico V-N permite crear con facilidad voces nuevas de significado reconocible, sobre todo si designan instrumentos o dispositivos. (NGLE, 2009: 745).

Es comprensible, pues, que no se incluyan todos los compuestos que se pueden crear a partir de este patrón regular de formación de palabras ${ }^{15}$, pero resulta incongruente que no explicite en los prólogos los criterios de introducción de estas voces (por qué aparecen unas y no otras), así como informaciones sobre su creación regular, tal y como se procede con los verbos regulares o con el superlativo sintético en -ísimo, por ejemplo.

A esto cabe añadir también la falta de sistematicidad de algunos diccionarios como el DRAE (2001) o el DUE a la hora de señalar los miembros que componen el compuesto en el paréntesis etimológico ${ }^{16}$. Puede observarse que no existe un criterio uniforme en ambas obras en esta cuestión y podemos hallar compuestos en los que se ofrece la información y otros casos similares en los que no. Esto se puede comprobar en compuestos como cortafuego $(s)$ - del que se señala que está constituido por el verbo cortar y el sustantivo fuego(s) y cortalápices, del que nada se indica acerca de sus componentes.

Para poder resolver el problema que supone desde el punto de vista lexicográfico la predictibilidad de algunos procesos de formación de palabras, sobre todo en el ámbito de la derivación, muchos diccionarios introducen los afijos como lemas. Así, según Díaz Hormigo (2009: 167):

[...] suele ser práctica habitual la inclusión como artículos independientes, en la macroestructura de estos diccionarios, [...] de los elementos que intervienen en la formación de palabras (fundamentalmente, prefijos, sufijos y raíces cultas de origen griego o latino), esgrimiéndose como razones para justificar el hecho de que se consignen estos elementos formativos, sobre todo, la economía de espacio y la imposibilidad de registrar como entradas del diccionario todos los resultados pertinentes de la formación productiva de palabras.

Esta metodología ha sido empleada desde los primeros repertorios lexicográficos, pero de una manera implícita, es decir, no se utilizaba el guion para dar cuenta de la naturaleza ligada de estos constituyentes ${ }^{17}$. Por ejemplo, el diccionario de Rodríguez Navas (1918: 4) justifica así la introducción de estos elementos entre sus lemas:

Cinco novedades comprende este Diccionario [...]. La segunda, es la de llevar en el vocabulario general incluidos los prefijos, infijos, subfijos y las raíces, desinencias y terminaciones de la lengua española, riquísima en estos

\footnotetext{
${ }^{15}$ Esto es lo que Pena (1994-1995: 168) denomina palabras no documentadas pero posibles.

${ }^{16}$ Estos son prácticamente los únicos diccionarios analizados que ofrecen la etimología de los lemas.

${ }^{17}$ En los diccionarios académicos la primera vez que aparecen explícitamente los afijos como lemas (es decir, marcados con el guion que indica su naturaleza dependiente) es en la edición de 1984 (vigésima edición).
} 
elementos compositivos [...] esta inclusión permitirá a toda persona que consulte el presente Diccionario interpretar cualquiera fórmula química, traducir cualquier neologismo o investigar la historia de una palabra, por la acción social y el influjo del tiempo.

Sin duda, esta metodología puede ayudar al usuario en el momento en el que busca tanto el patrón regular de formación de palabras como los significados que aporta el afijo. Así, podemos hallar como lemas del diccionario afijos como des- o -dor. Esta podría ser una posible solución para no introducir todas las palabras en las que interviene un elemento derivativo y cuyo proceso de creación es regular, ya que, según señala Martín García (2000: 1086), "el tratamiento de los afijos como lemas permite dejar abierto el proceso de creación léxica, en cuanto que quedan recogidas las palabras potenciales de una lengua".

Pese a que esta práctica, como se ha señalado, se había utilizado con las unidades afijales a principios de siglo XX, los diccionarios actuales también empiezan a realizar el mismo tratamiento para algunas unidades que intervienen en la creación de $\operatorname{compuestos}^{18}$ y que destacan por su alta productividad. Por ejemplo, podemos encontrar porta- (portaviones, portarretratos), italo- (italorromance) o socio- ${ }^{19}$ (sociocultural, sociolingüística) entre los lemas de diccionarios como el DEA, el DRAE (2001), el DUEAE o el DUE, elementos que en obras lexicográficas anteriores no aparecían en el lemario. Sin embargo, este tratamiento carece también de una aplicación sistemática. Se echa en falta, pues, otros formantes altamente frecuentes en la creación de compuestos como, por ejemplo, medio-, guarda-, saca- o -hablante. Mención aparte merecen los formadores de gentilicios como ítalo-, franco- o germano-. El análisis de estas unidades revela la discrepancia existente no sólo en cuanto a su incorporación en la macroestructura, sino también respecto a la metodología empleada en este sentido. Así, mientras el $D E A$ es el repertorio que reúne un número considerable de unidades creadoras de gentilicios y las trata como prefijos, otros diccionarios como el DUEAE o el DRAE (2001) se muestran más vacilantes, tal y como se resume a continuación:

\begin{tabular}{lccccc}
\hline & anglo- & franco- & indo- & ítalo- & germano- \\
\hline$D E A$ & Sí & Sí & Sí & Sí & Sí \\
$D R A E(2001)$ & No & Sí & No & Sí & Sí \\
$D U E A E$ & Sí & Sí & No & No & Sí \\
$D U E$ & Sí & No* & Sí & No & No* $^{*}$ \\
\hline
\end{tabular}

${ }^{18}$ Dejamos aparte los elementos grecolatinos que intervienen en la composición culta, ya que se tratan en el siguiente apartado de esta investigación.

${ }^{19}$ Las denominaciones que reciben estos elementos difieren según los diccionarios. El DRAE (2001) los considera elementos compositivos; el $D U E$, elementos prefijos/sufijos; y el $D U E A E$, elementos prefijales/sufijales. Este desajuste terminológico se acentúa en el caso de los formantes cultos, tal y como se analizará en la segunda parte de este trabajo. 
Resulta curiosa la metodología utilizada por el $D U E$ en el tratamiento de estas unidades. En algunas ocasiones, como en el caso de franco- o germano-, no aparecen entrados como formadores de palabras (es decir, como lemas independientes) sino que aparecen bajo la voz correspondiente, como una nueva acepción, en la que se indica "Se usa como prefijo con el significado de" 20 .

Finalmente, y siguiendo el criterio de sistematicidad presente en toda la obra, el $D E A$ incluye también en su lemario aquellas unidades que se utilizan en el ámbito de los colores (verdi- o roji- ${ }^{21}$ ) y al de otro tipo de asociaciones como, por ejemplo, social-. En nuestra opinión, la metodología del DEA debería servir de modelo a otras obras lexicográficas en cuanto al tratamiento de este tipo de unidades, pese a no compartir la concepción de todas ellas como prefijos.

A pesar de este intento de introducir también creadores de compuestos entre los lemas de los diccionarios, en la entrada lexicográfica de estas unidades (igualmente en la de los afijos) no se proporcionan informaciones sobre su empleo. De hecho, investigadores como Caluwe y Taeldeman (2003: 117) han señalado que en los lemas de los afijos, y, en nuestra opinión, también en los elementos formadores de compuestos altamente productivos, deberían consignarse datos sobre su forma, su pronunciación, la categoría gramatical de su base y sus rasgos fonológicos, la categoría gramatical resultante, su significado, aspectos pragmáticos, su productividad y ejemplos. Sólo teniendo en cuenta todos estos criterios cualquier diccionario podrá usarse no solamente como descodificador, sino también como codificador. Así, según expone González Pérez (2002: 109):

[...] el diccionario sincrónico, como se ha señalado muchas veces, debe ser codificador y descodificador al mismo tiempo. Para conseguir este fin, han de manejarse todos los niveles de análisis de los lexemas que se incluyen y, además, ha de darse entrada a elementos sin significado léxico, e incluso a formas trabadas sin independencia gráfica (prefijos y sufijos) y lexías complejas, que teniendo independencia gráfica en sus componentes, poseen un significante múltiple unitario significativamente.

En definitiva, como se ha mostrado, en los diccionarios actuales también se produce una falta de sistematicidad en el tratamiento de este tipo de unidades debida a la ausencia de unos criterios consistentes a la hora de efectuar su caracterización y el olvido, en ocasiones, de su doble función descodificadoracodificadora.

\footnotetext{
${ }^{20}$ Estos casos se han marcado con un asterisco en el cuadro.

${ }^{21}$ El DUE también incluye roji como lema dentro de su macroestructura.
} 


\subsection{Los compuestos con guion}

Otra de las cuestiones que plantean problemas de carácter lexicográfico es el tratamiento de los compuestos con guion. Este tipo de formaciones se conciben morfológicamente como un fenómeno híbrido: por un lado, su cercanía a la sintaxis provoca que muchos de ellos sean tratados dentro de los compuestos sintagmáticos o incluso como creaciones ocasionales; por otro, la presencia del guion implica la unión conceptual de los dos elementos, por lo que actúan como compuestos léxicos.

Este particular comportamiento del guion se señala en la reciente Ortografía de la lengua española publicada por la Real Academia y la Asociación de Academias de la Lengua Española:

Gracias a la naturaleza en cierto modo dual del guion, que une a la vez que separa, existe además la posibilidad de utilizar este signo para formar determinado tipo de compuestos, en los que se unen dos palabras entre las que se establece un estrecho vínculo semántico, a la vez que conservan cierta independencia referencial. (Ortografía, 2010: 411).

Este hecho provoca que podamos encontrar palabras formadas por composición con guion, fusionadas sin ningún tipo de enlace o bajo la forma de un compuesto sintagmático, con un espacio entre sus integrantes. De hecho, esta cuestión suele plantear bastantes dudas al hablante, pues es habitual que este vacile sobre el grado de fusión de los constituyentes y, por tanto, sobre el uso del guion en estos casos. Por ello, no extraña el hecho de que se pregunte cuál es la opción u opciones válidas en ejemplos como político-social politicosocial, coche cama coche-cama o disco-bar discobar ${ }^{22}$.

Esta cuestión, en un principio, debe ser resuelta en los compendios de ortografía, sin embargo, se traslada al ámbito lexicográfico cuando el lexicógrafo debe decidir la introducción de los compuestos con guion en el diccionario. A continuación, pues, se analizarán las consideraciones sobre el uso del guion en las obras ortográficas y de dudas académicas para corroborar si se solucionan los problemas que plantea el uso del guion en las palabras compuestas y las repercusiones que estas informaciones tienen desde el punto de vista lexicográfico.

Si acudimos a la ortografía, la solución hallada en, por ejemplo, la Ortografía de la Real Academia de $1999^{23}$, no es del todo satisfactoria, ya que sólo se ofrece información en las agrupaciones de dos adjetivos (teórico-práctico) y en

${ }^{22}$ Una búsqueda en el CREA (Corpus de Referencia del Español Actual) del compuesto buque escuela buque-escuela refleja claramente la vacilación existente en torno al uso del guion. Se han hallado 46 casos en 12 documentos para la variante con guion y 28 casos en 15 documentos para la formación sin este enlace.

${ }^{23}$ En la primera ortografía académica (1770) sólo se señalan los usos del guion en la separación de sílabas y en la división de palabras a final de renglón. 
los compuestos gentilicios señalando que "si el compuesto resultante se siente como consolidado, lo escribiremos sin guion" (Ortografía, 1999: 83). Esta consideración se muestra insuficiente e incompleta, ya que no se detallan todos los casos en los que se permite el uso del guion, a la par que deja la solución a la subjetividad del hablante.

Un tratamiento más minucioso se puede hallar en el Diccionario panhispánico de dudas (DPD) y en la nueva Ortografía (2010), ya que analizan los ejemplos de forma más pormenorizada atendiendo a su distinta tipología. En primer lugar, distinguen en función de la categoría gramatical de los elementos que se unen mediante el guion. Si son sustantivos, se señalan tres posibilidades:

a) Se puede usar el guion para crear compuestos ocasionales que hacen referencia a un concepto unitario. Añade el DPD (2005: s. v. guion ${ }^{2}$ o guión) que "este tipo de compuestos puede escribirse también sin guion, con espacio intermedio. Esto ocurre cuando la aparición conjunta de ambos sustantivos se generaliza en el uso y el concepto unitario que ambos designan pasa a formar parte del léxico asentado". Se ofrecen como ejemplo voces como sofá cama o ciudad dormitorio. Según se expone en la Ortografía (2010: 417), el guion parece ser un índice de la ausencia de generalización de la voz, ya que, cuando esta se difunde, es habitual que se elimine esta marca. Parece, pues, que en estas ocasiones, no debería aparecer en el diccionario el compuesto con guion, pues se considera que la formación está asentada en la lengua cuando no media este signo y, por tanto, sólo debería incluirse el compuesto sin fusión gráfica.

b) Se puede emplear esta marca con el valor de una preposición o una conjunción con el propósito de establecer relaciones tanto fijas como circunstanciales. En este sentido, sólo aquellas voces complejas con guion en las que se dé una unión lógica deben figurar en el diccionario. El DPD ilustra este uso del guion con voces como kilómetros-hora o calidad-precio. Pese a tener esta "relación fija" entre sus componentes, estas agrupaciones no figuran entre los lemas, por ejemplo, del DRAE (2001) o del DUE. En estos casos, la lista de relaciones fijadas puede no ser demasiado amplia, por lo que sería interesante reflejarla en los diccionarios.

c) Se puede utilizar de manera similar al de una conjunción donde los dos sustantivos se refieren a un único referente (por ejemplo, director-presentador). Se trata de un procedimiento no recomendado además de ocasional, por lo que es el que menores problemas plantea, ya que su inclusión en los diccionarios no es pertinente.

En segundo lugar, cuando los dos elementos son de categoría adjetival, se prescriben dos usos:

a) Se puede emplear el guion en los gentilicios, al igual que se efectuaba en la Ortografía (1999). Sin embargo, el DPD (2005: s. v. guion ${ }^{2}$ o guión) es más explícito a este respecto: 
Si en el sustantivo al que se aplica el gentilicio compuesto se fusionan los caracteres propios de cada uno de los elementos que lo forman no se escribe guion entre ellos [ciudad] hispanorromana, [ciudadano] francocanadiense, [dialecto] navarroaragonés [...]. Si lo que se desea es poner en relación dos adjetivos gentilicios que conservan su referencia independiente, se escribe guion entre ambos: [relaciones] germano-soviéticas, [frontera] chileno-argentina, [cumbre] luso-española"24.

En estas ocasiones, pues, el diccionario debe entrar los gentilicios con fusión gráfica y no aquellos con un guion de enlace.

b) Se puede usar en la aplicación de dos adjetivos calificativos o relacionales a un sustantivo cuando el primero de ellos conserva su forma plena (lingüístico-literario), ya que si este se acorta a modo de prefijo, se une sin mediación de un guion (socioeconómico) ${ }^{25}$. En estos ejemplos, a nuestro juicio, faltaría señalar que estas formaciones, cuando se generalizan en su uso y presentan una relación semántica estrecha, pueden perder el guion y, como consecuencia, los dos miembros que las integran acaban fusionándose gráficamente. Esto ha sucedido, por ejemplo, con físico-químico, que suele escribirse junto y sin guion (fisicoquímico). Si se da esta situación, el diccionario debería consignar ambas formas. De todos modos, cabe tener presente que esto puede variar desde el punto de vista geográfico, ya que según se expone en la NGLE (2009), existen zonas del español americano en las que no suele emplearse el guion y se fusionan los miembros sistemáticamente, mientras que en otros países se prefiere el uso del guion o cualquier otro procedimiento que evite el adjetivo compuesto.

Si analizamos estas informaciones, el uso del guion, de manera general, se concibe como una forma circunstancial de unir dos conceptos que, por tanto, suelen aparecer normalmente separados pero que se unen ocasionalmente. De hecho, tal y como señala la NGLE (2009: 763) "pueden ser creados espontáneamente para satisfacer las necesidades de un contexto particular". Pero, además, el guion también parece mostrar la falta de cohesión de dos elementos que, por ello, no pueden fusionarse o aparecer sin mediar entre ellos esa marca. En definitiva, como se desprende de algunas de las observaciones del diccionario de dudas académico, el uso del guion es una opción individual ya que el usuario es el que decide en última instancia cuál es la relación que quiere expresar entre los dos miembros de la formación. Así, las ortografías y el diccionario de dudas abogan mayoritariamente por la pérdida del guion cuando la palabra compleja está asentada en la lengua, lo que puede implicar dos soluciones: o

\footnotetext{
${ }^{24}$ Las mismas consideraciones sobre esta cuestión se hallan expuestas en la NGLE (2009: § $11.6 \mathrm{~g}-11.6 \mathrm{j})$ y en la Ortografía (2010).

${ }^{25}$ La NGLE (2009: § 11.6g) añade que "se aconseja también el uso del guion también cuando el radical en $o$ (ruso) coincide con la forma libre (ruso)".
} 
bien la fusión de los dos constituyentes en un compuesto léxico o bien la creación de un compuesto sintagmático. Sólo estos dos resultados (compuesto léxico y sintagmático) deben tener cabida en los compendios léxicos, por lo que las agrupaciones con guion, al ser ocasionales, están exentas de formar parte de los lemas de cualquier diccionario general.

Sin embargo, es posible observar que los repertorios lexicográficos sí que incluyen palabras complejas en las que media un guion. Esta práctica, que podría pensarse que es bastante reciente, ya se encuentra en diccionarios como los de Terreros (1786) (sota-bibliotecario) o Domínguez (1853) (sobre-aguja, ultra-analogista), aunque su uso, como se deduce de los ejemplos aportados, se atestigua en casos en los que aparece una preposición a modo de prefijo y se emplea para dar cuenta, seguramente, de la predictibilidad de su creación o bien para marcar la independencia de la preposición respecto de la base.

Los diccionarios actuales también incorporan palabras con guion entre sus lemas, aunque no son muy numerosas. El problema no es tanto su introducción en los diccionarios, sino la falta de criterios a la hora de incluirlas y la discordancia existente entre las distintas obras.

Así, el $D E A$ es el diccionario que muestra menores restricciones a la hora de incorporar compuestos con guion. Para dar cuenta de si un compuesto se escribe con ese signo ortográfico o sin él, se utiliza la remisión (por ejemplo, cóctel bar, coche restaurante o coche cama remiten a sus respectivas variantes con guion cóctel-bar, coche-restaurante y coche-cama) o el paréntesis tras el lema en el que se indica la variación gráfica (por ejemplo, en ciencia ficción se señala que también puede escribirse con la grafía ciencia-ficción o que hombreanuncio puede emplearse con la grafía hombre anuncio).

Otros repertorios como el DRAE (2001), el DUE o el DUEAE no ofrecen esa opción, ya que únicamente se recoge la que no presenta guion ${ }^{26}$, como en ciencia ficción, casa cuartel, cartón piedra o fútbol sala.

Sin embargo, en nuestra opinión, debería proporcionarse la variación gráfica mediante guion, siguiendo la metodología del $D E A$, a aquellos ejemplos suficientemente documentados y en los que esa marca ortográfica ejerce una función unificadora (no cuando su papel es constatar la circunstancial agrupación de dos elementos), ya que quizás la formación con guion sea el paso previo de que en el futuro pueda llegar a fusionarse gráficamente. Es decir, en buque escuela debería señalarse que también se documenta el compuesto con guion y que ambas variantes son igualmente válidas.

Si bien es cierto, tal y como se ha mostrado, que en los manuales ortográ-

${ }^{26}$ Esto no significa que no aparezcan, aunque de forma muy escasa, compuestos con guion. Por ejemplo en el DRAE (2001) se encuentran café-teatro o café-cantante y en el DUE se puede hallar mueble-bar. 
ficos se ofrecen los usos del guion en la creación de compuestos, los diccionarios podrían convertirse en una herramienta mucho más ágil que una ortografía en la resolución de las dudas que los hablantes suelen tener sobre si una determinada formación puede o no llevar guion y, sobre todo, cuál es la opción más frecuente. Por ello, "a pesar de la frecuencia de uso relativamente extendida que tienen los compuestos con guión de unión en la lengua escrita, no se los ha tratado todavía de forma particular" (Minghetto, 1989: 334). Quizás, gracias a la lexicografía, se podría empezar a llenar ese vacío.

\section{TRATAMIENTO LEXICOGRÁFICO DE LA COMPOSICIÓN CULTA}

Se conocen con el nombre de compuestos cultos aquellas palabras complejas que o bien están constituidas por dos unidades de procedencia culta como,

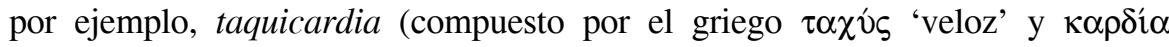
'corazón') o bien son híbridas, por lo que presentan entre sus formantes uno de origen culto y otro patrimonial, como en aeronave (del griego $\alpha \varepsilon ́ \rho$ 'aire' y el español nave). Así, "el español hereda del latín no solo palabras (a modo de continuación en las formaciones populares y a modo de incorporación intermitente en las formaciones cultas), sino también pautas o reglas en la formación de palabras cultas" (Pena, 1994-1995: 178).

Como es bien sabido, la composición culta se halla vinculada a los lenguajes de especialidad. Por ello, aunque este tipo de compuestos ya se utilizaba como mecanismo de creación de palabras desde el siglo $\mathrm{XIII}^{27}$, su auge se produce a partir del siglo XVIII, precisamente la época en la que se desarrollaban la mayoría de los avances técnicos y científicos. El aumento de esta clase compositiva continuó en el siglo XIX y se puede considerar que es una tendencia que prosigue en la actualidad. De hecho, Guerrero Ramos y Pérez Lagos (2009: 66) señalan que:

[...] el llamado procedimiento de composición culta, habitualmente empleado para la formación de vocabulario técnico y científico (con un funcionamiento interno similar al de las antiguas composiciones griegas y latinas: determinado + determinante) cada día es más empleado [...] para las nuevas necesidades léxicas que el hablante común siente diariamente.

La composición culta, sin embargo, no tiene demasiada presencia en los manuales de morfología ${ }^{28}$. Una posible explicación podría estar en los proble-

${ }^{27}$ La documentación más temprana de un compuesto culto según el $D E C H$ data de este siglo.

${ }^{28}$ Por ejemplo, el trabajo de Bustos Gisbert (1986), pese a ser una de las obras más importantes sobre la composición en español, no tiene en cuenta la composición culta. Sólo estudios morfológicos como el de Val Álvaro (1999) y el capítulo dedicado a la composición de la NGLE 
mas que plantea desde el punto de vista descriptivo y metodológico, ya que no existe un acuerdo en relación a la naturaleza de estos elementos cultos: ¿su comportamiento es afijal $\mathrm{y}$, por tanto, crearían derivados, o se trata de formadores de compuestos? Pese a esta problemática, lo que es ineludible es la necesidad de incluir las palabras complejas en las que intervienen en los diccionarios, máxime si tenemos en cuenta su altísima productividad en el español actual, tal y como se ha señalado. Por tanto, se traslada al ámbito lexicográfico una de las cuestiones más controvertidas desde el punto de vista morfológico: la naturaleza de las unidades que intervienen en la composición culta.

\subsection{Naturaleza de los elementos cultos: cuestiones terminológicas}

Desde el punto de vista de la historia de la lexicografía, cabe efectuar una distinción en cuanto a la presencia de estas unidades cultas en los diccionarios. Así, mientras aquellas cuyo origen es una preposición o adverbio griego o latino (infra, meta, retro ${ }^{29}$ ) aparecen desde los primeros compendios lexicográficos (aunque se hallen pocos ejemplos), aquellas que proceden de sustantivos o adjetivos grecolatinos empiezan a hacerse un hueco en los repertorios de finales del siglo XIX y principios del XX (aden, algia, hidro). Los casos más antiguos que se han hallado pertenecen al Diccionario de autoridades:

PROTO. Voz Griega, que vale Primero en su línea, y sirve en composicion de otras voces de aquella lengua: y también se ha extendido a componer algunas españolas, y aun a inventar muchas en el estilo jocóso: como Protopobre, Protodiablo, \&c. (Aut.: s. v. proto).

SOTA. Se usa en composicion, para significar el subalterno inmediato en algunos oficios y empleos: como Sotacaballerizo, sotacochero, sotacomitre, \&c. Suele usarse esta voz sola diciendo el Sota. (Aut.: s. v. sota).

Otra cuestión que se aprecia en la historia lexicográfica es la variedad de denominaciones ${ }^{30}$ que aparecen no sólo en los distintos diccionarios sino también a la hora de clasificar las unidades cultas del mismo tipo, tal y como se puede observar en el siguiente cuadro:

(2009) (aparte de algunos trabajos de carácter monográfico) han incluido este tipo de formaciones dentro de la composición.

${ }^{29}$ No empleamos guiones para marcar la consideración como formadores de palabras de estos elementos porque los primeros diccionarios que los recogen como lemas no hacen uso de esta metodología. En el $D R A E$ (1970) es la primera vez que se lematizan estas unidades seguidas de guion.

${ }^{30}$ Para un estudio más detallado de los términos usados en la designación de estos elementos en la lexicografía académica y extraacadémica del siglo XX, véase Torres Martínez (2008). 


\begin{tabular}{llll}
\hline & \multicolumn{1}{c}{ infra } & \multicolumn{1}{c}{ meta } & \multicolumn{1}{c}{ retro } \\
\hline DRAE (1884) & - & preposición inseparable & partícula prepositiva \\
Zerolo (1895) & palabra latina & - & partícula prepositiva \\
Rodríguez Navas (1918) & tema & prefijo & prefijo \\
\hline
\end{tabular}

De esta variedad terminológica se desprende la dificultad que ya antiguamente existía respecto a la clasificación de estos formantes cultos, incluso aquellos de origen preposicional o adverbial. Sin embargo, más allá de la heterogeneidad de denominaciones, se puede llegar a observar que las obras lexicográficas más antiguas dan cuenta de la autonomía de estos elementos cultos (y su pertenencia, por tanto, a la composición de palabras). Aunque esta consideración se repite en repertorios posteriores en función del formante grecolatino ${ }^{31}$, los diccionarios señalan la pérdida de autonomía que experimentan estas unidades con el paso del tiempo, a través del término utilizado para su clasificación. Así del empleo del concepto "voz" o "palabra", se pasa al de "preposición o partícula inseparable", es decir, se indica su naturaleza ligada. Finalmente, y en algunos ejemplos muy concretos, determinados diccionarios clasifican estas unidades como prefijos. Tal es el caso de proto, considerado así a partir de la edición del diccionario académico de 1884 (tratamiento que seguirán obras posteriores), o retro y ultra que también son calificadas como prefijos en Rodríguez Navas (1918).

La tendencia a situar estos elementos entre los prefijos se acentúa en los repertorios lexicográficos a partir de la segunda mitad del siglo XX y continúa en los diccionarios actuales (como el DEA o el DUE). En este sentido, los diccionarios académicos siguen un camino distinto, ya que el estatuto que confiere a este tipo de unidades es el de elemento compositivo ${ }^{32}$, tratamiento que se extiende hasta la última edición. Sin embargo, en nuestra opinión, el comportamiento de estas unidades las acercarían más a los afijos y, por tanto, así deberían ser clasificadas en los repertorios lexicográficos.

Respecto a las unidades cultas cuya procedencia es un sustantivo o adjetivo grecolatino, ya se ha señalado que aparecen por primera vez en la lexicografía en el siglo XIX y principios del siglo XX. Los repertorios que suponen un punto de inflexión en este sentido son los de Salvá (1846), Domínguez (1853), Zerolo (1895), Toro y Gómez (1901) y, sobre todo, el de Rodríguez Navas (1918). Aquí, también se observa la divergencia en la clasificación en los distintos repertorios y la variada terminología que sigue la misma pauta que la analizada para las unidades cultas de origen prepositivo y adverbial:

${ }^{31}$ Sirva como ejemplo, que el diccionario de Domínguez (1846-1847: s. v. ultra), indica que ultra es una "Voz latina que entra en la composicion de muchas voces [...]" o que el repertorio de Zerolo (1895: s. v. infra), señala que infra es una "Palabra latina que entra en la composicion de muchos vocablos y que significa debajo".

${ }^{32}$ Más adelante, tratamos las cuestiones en cuanto a esta denominación. 


\begin{tabular}{llll}
\hline & \multicolumn{1}{c}{ aden } & \multicolumn{1}{c}{ algia } & \multicolumn{1}{c}{ hidro } \\
\hline Domínguez (1846-1847) & voz griega & voz griega & palabra griega \\
Zerolo (1895) & palabra griega & palabra griega & prefijo \\
Toro y Gómez (1901) & prefijo griego & prefijo griego & prefijo griego \\
Rodríguez Navas (1918) & tema & sufijo o desinencia & prefijo \\
\hline
\end{tabular}

Se observa, sin embargo, una preferencia en gran parte de los casos por considerarlas "palabras" independientes de origen culto que se usan en composición aunque también es posible hallar denominaciones como "terminación", "raíz" o incluso la de simplemente "elemento" o "forma":

NECRO, (del gr. necros muerte). Raiz de muchas palabras como: [...] (Domínguez, 1846-1847: s. v. necro).

HEMA, HEMO, HEMAT, HÉMATO. Formas castellanas de las voces griegas haima, haimatos, que significan sangre. (Zerolo, 1895: s. v. hema, hemo, hemat, hémato).

FILIA. Terminación de voces, como bibliofilia, aliadofilia, anglofilia, usada como s. f. para indicar apasionada simpatía por alguna cosa. (DRAE, 1927: s. v. filia).

Sin duda, la obra que representa un salto cuantitativo y cualitativo respecto al tratamiento de estas unidades cultas es el diccionario de Rodríguez Navas (1918). Resulta bastante lógico que los elementos cultos que se están analizando aparezcan en un diccionario como este, ya que este incorpora tecnicismos, es decir, terminología perteneciente a lenguajes de especialidad. Por ello, son de especial importancia las consideraciones que realiza en el prólogo:

Supóngase que alguien desea averiguar el valor de una fórmula farmacéutica, tal como fenoldimetilonamidonsulfotosódico. No la encontrará en el Diccionario; pero si la descompone en sus elementos fenol-di-metil-on-amidonsulfo-ato-sód-ico, sabrá, mediante la ayuda de este Diccionario, que aquella fórmula es la de un compuesto de sal procedente del ácido fénico, doble cantidad de metano, una parte de acetona y otra parte de sal de ácido sulfónico y sodio. (Rodríguez Navas, 1918: pág. 4, nota 1).

Sin embargo, la distinta denominación que reciben estas unidades refleja claramente la dificultad que supone delimitarlas:

Fona, Fone, Foni, Fono. Fil. Temas de voces tales como fonación, foneidoscopio, fonigrama, Fonología y otras. (Rodríguez Navas, 1918: s. v. fona, fone, foni, fono).

Metría, Métrico, Metro. Fil. Sufijos o desinencias de voces tales como Geometría, goniométrico, higrométrico y otras. (Rodríguez Navas, 1918: s. v. metría, métrico, metro).

Zoo. Fil. Prefijo de voces tales como Zoología, Zootecnia y otras. (Rodríguez Navas, 1918: s. v. zoo). 
En la actualidad, también se incorporan estos formantes cultos en la macroestructura de los diccionarios pero, como los repertorios analizados hasta el momento, suelen heredar los problemas que se han apuntado. En primer lugar, de nuevo aparecen distintas denominaciones para la misma unidad según la obra de la que se trate. En segundo lugar, se produce un desacuerdo entre los elementos que estas recogen ${ }^{33}$. Además, en algunos repertorios lexicográficos se observa una discrepancia entre lo señalado en las indicaciones previas al uso del diccionario y la descripción de la unidad en la entrada lexicográfica. Finalmente, también es muy dispar la metodología empleada en la presentación de las distintas significaciones que aportan estas unidades en función de la obra consultada. A esta misma conclusión llega Pena (2002: 295) cuando afirma que el tratamiento que reciben estos formantes cultos en los diccionarios es bastante deficiente en tres ámbitos "variantes formales / distribución / significado".

En cuanto a la heterogeneidad en su denominación, esta es una cuestión que la lexicografía "hereda" de la morfología y de la tradición lexicográfica anterior, tal y como se ha mostrado. Ya hemos mencionado al principio del apartado precedente que la naturaleza de estos formantes cultos no está exenta de discusión. Almela (2003: 87) muestra una lista de términos documentados que se han utilizado para nombrar estas unidades:

seudo afijos, seudoprefijos, seudosufijos, elementos semiautónomos, compuestos sustitutivos, formas combinadas, formas prefijas y sufijas, palabrasprefijos y palabras-sufijos, elementos compositivos, elementos prefijales y sufijales, elementos con tendencia prefijal y sufijal, semipalabras, semiprefijos, semisufijos, afijoides, prefijoides, sufijoides, compuestos neoclásicos, recompuestos, raíces cultas, raíces prefijas y sufijas...

Estas denominaciones no hacen más que dar cuenta del comportamiento híbrido de estos elementos que ya se ha señalado: su falta de autonomía les conferiría un estatuto afijal (véase Alba de Diego, 1983), pero su comportamiento como formador de palabras los situaría en el terreno de la composición ${ }^{34}$. Así se señala en la NGLE (2009: § 11.10.b):

Algunas de las unidades léxicas grecolatinas mencionadas constituyen siempre el primer componente de la palabra y se asimilan, por su comportamiento formal, a los prefijos, [...]. En cambio, el estatuto de otras voces grecolatinas

${ }^{33}$ A esto cabe añadir la posibilidad de que el elemento culto sea también una palabra patrimonial como es el caso de fobia. Es decir, ¿consideramos que agorafobia está formada por dos elementos cultos (agora- y fobia) o por un elemento culto y una palabra patrimonial (agora- y fobia)?

${ }^{34}$ Los rasgos funcionales y semánticos que justificarían el tratamiento de estas unidades como formadores de compuestos se pueden encontrar en Almela (1999: 157-158) o en Torres Martínez (2008: 394). 
en la teoría morfológica es especial, ya que se considera que son exponente de una unidad morfológica distinta, llamada por lo general elemento compositivo o tema neoclásico, a medio camino entre un afijo y una forma libre.

Si se efectúa una cala en distintos diccionarios actuales, podemos observar también una gran divergencia terminológica ${ }^{35}$. La mayoría se decanta por considerarlos formantes más cercanos a la derivación que a la composición. Así el $D U E$ trata todas estas unidades como afijos y las incluye en el lemario, al igual que otros prefijos y sufijos prototípicos como des- o -dor. El DEA, por su parte, también los considera afijos, pero sólo aparecen entrados como lemas aquellos que se adjuntan delante de la base, es decir, los prefijos, mientras que los que se unen detrás, no aparecen en este repertorio.

Una posición más prudente la hallamos en el DUEAE, ya que la denominación empleada no es la de afijo, sino la de elementos prefijales (si se adjuntan al inicio) o sufijales (si se unen detrás). Aunque en esta obra no se manifiesta claramente que se trata de afijos, se puede deducir que así son considerados porque, en los cuadros gramaticales dedicados a la formación de palabras, no aparecen los compuestos cultos. Pese a ello, se puede comprobar la incoherencia al respecto que podemos hallar en las entradas de algunas de estas unidades. Por ejemplo, si consultamos el lema micro-, se señala que es un elemento prefijal. Sin embargo, en la etimología se precisa que "forma compuestos en los que se refiere tanto a objetos de pequeño tamaño (microbús, microcéfalo) como, por extensión, a la ampliación que producen de estos objetos (microscopio, micrófono)" (DUEAE: s. v. micro-). Como se puede apreciar, la naturaleza de estos elementos prefijales y sufijales no queda clara en este diccionario.

Otros repertorios como el DSLE son más restrictivos pues, pese a incorporar como lemas los afijos, no se da cuenta de los formantes cultos que se están analizando. Únicamente se hallan en la microestructura aquellos cuya significación es más cercana a la de una preposición o un adverbio, como, por ejemplo, auto-, infra-, poli-, proto-, retro-, tele- y vice-, considerados todos ellos prefijos, pero se echan en falta, si seguimos este criterio semántico, otros como hiper-, hipo-, circu(n m)-, ecto-, endo-, meta- o ultra-, máxime si tenemos en cuenta que sí que aparecen entradas las palabras en cuya formación intervienen.

Por su parte, el DRAE, por ejemplo, desde la edición de 1970 apuesta por la denominación de "elemento compositivo". Según señala Torres Martínez (2008: 397):

[...] al emplear el término "elemento compositivo", el DRAE (1992) parece que intenta unificar las categorías asignadas a las distintas unidades a fin de homogeneizar su nomenclatura y evitar incoherencias, puesto que la etiqueta

${ }^{35}$ Véase a este respecto también el trabajo de Bernal Gallén (2009). 
"elemento compositivo" reconoce la naturaleza ligada de las formas objeto de estudio, consideración que no era contemplada en las ediciones de 1914, 1936 y 1970 cuando se empleaba la denominación "preposición inseparable" a la hora de definir algunas unidades.

Este término es tomado también por el diccionario CLAVE con un pequeño matiz que resulta, por lo pronto, chocante. En este diccionario, la posición es lo que distingue un elemento compositivo de un prefijo. Así, mientras las unidades cultas pospuestas se tratan como sufijos (y se incorporan a una lista de sufijos que evita su incorporación como lemas en el diccionario), las formas grecolatinas antepuestas se consideran elementos compositivos y, además, se tratan como lemas. Esto hace que podamos encontrar "antropo" clasificado de dos maneras distintas: antropo- es un elemento compositivo y -antropo se considera sufijo.

En cuanto a las denominaciones que aparecen, resulta curioso que ninguno de los diccionarios examinados utilice los términos tradicionales de afijoide (que, a su vez, incluye el de prefijoide y sufijoide ${ }^{36}$ ) acuñado por Malkiel (1993) o seudoafijo (junto con seudoprefijo y seudosufijo), que sí que han tenido bastante uso en la bibliografía sobre morfología (véase, por ejemplo, Alvar Ezquerra, 1993 o Lang, 1992).

Otros nombres que se han asignado a estas unidades dentro de la morfología y que tampoco han tenido éxito en los compendios lexicográficos han sido los de tema grecolatino o raíces ligadas empleados por Val Álvaro (1999: § 73.1.5) o Varela y Martín García (1999), denominaciones que reflejan que estas unidades no están fonológicamente cerradas y que, en ocasiones, pueden tener la forma de una raíz. Esto permitiría dar cuenta de las variaciones alomórficas que pueden manifestar (-grafía, -grafo), de la ausencia de restricciones de adjunción en algunos casos al poderse adjuntar en cualquier posición de la palabra, e incluso de sus peculiaridades combinatorias al poder unirse varios de ellos simultáneamente. En esta línea se halla también la propuesta de Pena (2002), pues los considera también temas de palabras inexistentes que son constituyentes de temas de palabras derivadas o compuestas. Según este autor, "son temas que nunca aparecen solos como temas de palabras simples, sino en combinación con un afijo o con otro tema" (Pena, 2002: 295). En cualquier caso, estos temas grecolatinos generarían compuestos, no derivados.

Aunque tanto los términos "elemento compositivo" como tema culto o grecolatino nos parecen apropiados, pues muestran claramente la vinculación de estas unidades con la composición, consideramos que el empleo que el diccionario académico hace del primero de ellos es el de una especie de "cajón de

${ }^{36}$ Esta es la denominación empleada, por ejemplo, por el Institut d'Estudis Catalans en el DIEC (2007). 
sastre", ya que cataloga de "elemento compositivo" unidades tan distintas como ante-, alti- o bio-. Por ello, en nuestra opinión, cabe efectuar una caracterización más precisa de estos formantes (véase Buenafuentes de la Mata, 2008) y distinguir claramente los que son prefijos (ante-, circum-, super-, etc.), de los que únicamente son elementos compositivos (alti-, germano-, socio-, etc.) de aquellos que, además de serlo, son temas cultos ${ }^{37}$ (bio-, hidro-, hemato-, etc.).

\subsection{Inclusión de las unidades cultas en los diccionarios}

La segunda de las cuestiones planteada que se desprende de la descripción de estas unidades en los diccionarios es la divergencia entre el número de voces creadas mediante este mecanismo que figuran en cada obra, así como los elementos que se recogen (véase Torres Martínez, 2008). Evidentemente, que la cantidad de palabras creadas mediante la composición culta varíe está motivada muchas veces por los objetivos del propio diccionario, ya que, por ejemplo, los de uso recogerán únicamente aquellas que son frecuentes en el uso actual. Pero el tratamiento lexicográfico de este tipo de unidades va más allá, ya que pone en evidencia otra de las cuestiones controvertidas en el terreno lexicográfico: la inclusión del léxico de especialidad en el diccionario. Además, tal y como señalan Guerrero Ramos y Pérez Lagos (2009: 75), "dentro de este grupo de elementos creadores sólo unos pocos resultan altamente productivos". ${ }^{38}$ En este sentido, únicamente deberían entrar en el diccionario aquellas en las que intervienen unidades cultas que han permeado al léxico general y cuyo índice de frecuencia y productividad es alto. De este modo, según García Platero (2000: 428),

Se pueden excluir de la macroestructura del diccionario las voces pertenecientes a dominios de especialidad si no se han generalizado en su uso. Del mismo modo, pueden dejarse a un lado los seudoafijos en el momento en que se utilizan exclusivamente en la creación de estos vocablos sectoriales. El problema viene cuando se emplean determinados elementos sufijales en dominios distintos de los que, en un principio se esperaba.

En nuestra opinión, el empleo de estas unidades fuera del lenguaje de especialidad que las originó supone un proceso de generalización o banalización

${ }^{37}$ Sin embargo, es importante tener en cuenta que determinadas unidades cultas, por distintos motivos, pueden experimentar un proceso de gramaticalización, semejante al que sufrieron los sufijos -mente (procedente del sustantivo latino mens, tis) o -ficar (que deriva del verbo latino facere), que las convierta en afijos. Para un análisis detallado de este proceso diacrónico, véase Buenafuentes de la Mata (2006).

${ }^{38}$ Y añaden a continuación: "Así, con sólo ocho de los 27 considerados se producen 1390 de los neologismos recogidos (casi el 65 por ciento)". A esta misma conclusión se llega en Buenafuentes de la Mata (2006). 
(véanse Cabré, 1995; Adelstein, 1998). Este fenómeno de ampliación semántica se puede efectuar siguiendo dos vías. En primer lugar, el formante culto puede generar un nuevo significado a partir de su sentido originario. En palabras García Platero (2000: 429), la nueva significación proviene del "desarrollo de acepciones o valores secundarios respecto del sentido inicial". Son varios los trabajos que muestran claramente cómo estos elementos adquieren nuevos sentidos que, muchas veces, no se indican en los diccionarios. Por ejemplo, -dromo, que en su origen significaba 'carrera', ha pasado, en las formaciones más actuales como botellódromo, a tener el sentido de 'lugar'. También se da esta generalización en casos como -logía que pasa, de tener el sentido de 'tratado, disciplina', a designar 'conjunto de elementos' como en rumorología $a^{39}$; o el caso de -itis que en determinadas creaciones neológicas presenta el significado de 'afición desmedida' (por ejemplo mamitis), bastante alejada de su sentido originario especializado de 'inflamación' ${ }^{40}$. De hecho, en los diccionarios como el DRAE (2001), el CLAVE, el DUEAE o el DUE únicamente se señala el significado más técnico, el que se ciñe al lenguaje de especialidad, y no incorporan el que se ha originado por generalización. Sólo en el caso de -dromo, tanto en el CLAVE como en el DUEAE, la definición del elemento se limita al sentido ampliado de 'lugar', sin hacer constar el significado originario de 'carrera'.

La segunda de las vías para la generalización es que la voz sufra un acortamiento a partir del cual la parte acortada pasa a designar lo que significaba la voz en su totalidad. Ese acortamiento con esa nueva significación lexicalizada deja de concebirse como un elemento culto y se convierte en una nueva forma con un nuevo significado que interviene en la creación de otras palabras donde aporta ese nuevo sentido. Como se puede observar, el proceso descrito se relaciona estrechamente con otro procedimiento de formación de palabras denominado acronimia ${ }^{41}$.

Por ejemplo, $\operatorname{aer}(o)$ - interviene en numerosos compuestos con el significado de 'aire' como en aeronave. Sin embargo, ipresenta este sentido en palabras como aeroclub o aeromodelismo? La respuesta es que no, pues aero- en estos casos tiene la significación de 'aviación'. Lo mismo sucede con narco- 'sueño' (narcolepsia, narcótico), ya que es evidente que el significado que aporta este formante en narcosala o narcotraficante, por ejemplo, procede del acortamiento de narcótico 'droga'. Esta particularidad plantea también problemas desde el

\footnotetext{
${ }^{39}$ Véanse García Platero (2000) y Buenafuentes de la Mata (2012).

${ }^{40}$ García Platero (2000) estudia también otros cambios del mismo tipo en elementos como -cracia, -manía y -oide.

${ }^{41}$ Según Pena (2002: 296), la acronimia es un "procedimiento de formación complejo que resulta de la combinación simultánea de dos procesos simples: acortamiento y composición". En este trabajo, tratamos también estos casos de acronimia porque no dejan de ser un proceso compositivo.
} 
punto de vista lexicográfico, pues el tratamiento que reciben estos elementos grecolatinos es bastante heterogéneo. Lo más habitual es que se expresen en acepciones distintas los significados que aporta el elemento culto, tal y como se procede en el caso de los afijos polisémicos. Sin embargo, los distintos sentidos en los casos que se están analizando no deben aparecer bajo el mismo lema pues los orígenes son diferentes. Por ello, consideramos que deben consignarse en lemas homónimos separados, tal y como señala Pena (2002: 297). Así pues, el tratamiento lexicográfico debería ser el siguiente:

aer(o) ${ }^{1}$ elem. compos. Significa 'aire'. Aeronave

aer(o)- ${ }^{2}$ elem. compos. Del acortamiento de aeronave. Significa 'aviación, aeronave'. Aeromodelismo, aeroclub.

narco- ${ }^{1}$ elem. compos. Significa 'sueño'. Narcolepsia.

narco- ${ }^{2}$ elem. compos. Del acortamiento de narcótico. Significa 'droga'. Narcotraficante, narcodólar.

En definitiva, compartimos la opinión de Cabré (1995: 282) cuando afirma que:

La banalització semàntica hauria de prevaldre per sobre de la seva precisió especialitzada. [...] els termes que s'inclouen en un diccionari general, més que conservar el seu estatus de termes, han passat a adquirir l'estatus de mots, perdent, doncs, la seva especificitat temàtica restrictiva que els feia propis només de la comunicació professional.

\section{CONCLUSIONES}

Es evidente que la lexicografía se ha enfrentado y se enfrenta en la actualidad con problemas que en ámbitos como la sintaxis o la morfología todavía son fuente de discusión. En el caso de la morfología, la dificultad de diferenciar entre los distintos procesos de formación de palabras, sobre todo la distinción entre prefijación y composición, se aprecia, según se ha mostrado, sobre todo en los primeros repertorios lexicográficos que tienden, mayoritariamente, a situar la prefijación como un tipo de composición. La teoría morfológica basaba la definición de palabra compuesta en la autonomía de los elementos que la integraban y eso implicaba que vocablos como sobrevolar o contrarrestar se consideraran compuestos. Esto, añadido a la consideración de los prefijos como antiguas preposiciones y adverbios y, por tanto, con autonomía funcional, también apoyaba la tesis de que descolocar o innecesario eran compuestos y que, por consiguiente, la prefijación era un mecanismo compositivo.

En la actualidad, se ha señalado que "el criterio formal de distinción basado en la condición de "forma libre" de los constituyentes del compuesto se mues- 
tra insuficiente" (Varela, 1992: 97) y que el comportamiento de la prefijación se sitúa más cercano al de la derivación que al de los mecanismos compositivos. Este cambio en la teoría morfológica, como se ha visto en esta investigación, se muestra claramente en los diccionarios más actuales, donde ya no se asocia lexicográficamente la prefijación a la composición.

Fuera de la teoría morfológica estricta, la lexicografía tiene la difícil tarea de cumplir una doble función codificadora-descodificadora. Los diccionarios no deben dar cuenta de todas las voces que pueden crearse mediante los mecanismos de formación de palabras, pero sí que deberían, en la medida de lo posible, facilitar las herramientas que permitan a los hablantes poderlas construir o interpretar. Esto se ha venido haciendo en los repertorios lexicográficos gracias a la lematización de los afijos. En nuestra opinión, esta práctica debería extenderse también en el caso de los elementos compositivos, es decir, en aquellas unidades que se utilizan frecuentemente en composición (afro-, blanqui-, socio-, etc.). Además, como se ha señalado, cabría revisar las informaciones que se ofrecen en estas entradas y sistematizarlas, pues en ocasiones faltan muchísimos datos acerca del uso de estos formantes que son necesarios para codificar y descodificar las palabras complejas en las que intervienen.

Otra de las funciones que solemos asignarles a las obras lexicográficas es la de referente en cuanto al uso correcto de una palabra, es decir, le conferimos al diccionario el papel de legitimador (sobre todo aquellos que tienen carácter normativo). Por ello, debido al complejo uso del guion en las palabras compuestas, parece necesario su tratamiento fuera de los tratados ortográficos. Pese a que el hablante es consciente de que el uso del guion parece ser el de juntar "ocasionalmente" dos palabras, también debe conocer que, en algunos casos, esa unión es tan estrecha que la forma con guion puede llegar a convertirse en un paso previo a la fusión de las dos unidades en un compuesto léxico, y que, por tanto, el uso del guion es totalmente válido. En consecuencia y teniendo en cuenta el empleo tan extendido en la prensa escrita, los compuestos con guion deberían tener un mayor reflejo en los diccionarios, siempre y cuando se hallen documentados frecuentemente $\mathrm{y}$, además, se den entre los dos miembros una relación fija que permita considerarlos una unidad.

Finalmente, uno de los problemas que todavía se debate en el ámbito morfológico es el de la naturaleza de la composición culta hasta el punto de que en muchos manuales de morfología no se considera un tipo compositivo. Ello se debe a que el estatuto de los elementos cultos que se emplean en la formación de palabras como aeronave o biodiversidad está a caballo entre la derivación y la composición. Fruto de esta divergencia es la variabilidad terminológica existente a la hora de denominarlos tanto en el terreno morfológico como en el lexicográfico, algo que se manifiesta desde los primeros diccionarios que incluyen en su macroestructura estas unidades cultas, como 
se ha mostrado en este trabajo. En este sentido, cabe hacer una distinción entre aquellos que proceden de una preposición o adverbio grecolatino de aquellos que derivan de un sustantivo o adjetivo. En el primer caso, se documentan en los primeros repertorios lexicográficos y progresivamente van asociándose a los prefijos (aunque cabe tener presente que, como se ha visto, la prefijación no tiene estatuto independiente de la composición hasta épocas muy recientes). En el segundo, los primeros diccionarios suelen indicar de manera general que son palabras autónomas, aunque también se hace patente la falta de sistematicidad en su denominación. En la actualidad, en cambio, obras como el $D E A$ o el $D U E$ suelen clasificarlos mayoritariamente como formantes más cercanos a la afijación, aunque existen casos como el DRAE o el CLAVE que los considera elementos compositivos y, por tanto, creadores de compuestos. Como se ha demostrado en esta investigación, estas unidades, que son clasificadas conjuntamente, ya sea como afijos o como elementos compositivos (según el repertorio lexicográfico), no actúan del mismo modo. Por ello, cabe distinguir aquellas cuyo origen es una preposición o adverbio grecolatino, que deben considerarse afijos, pues su comportamiento es más cercano a la derivación, y aquellas cuyo origen es un sustantivo o un adjetivo, ya que estatuto será el de elemento compositivo (denominación que muestra su capacidad para generar compuestos) y tema culto (término que refleja su procedencia culta y su naturaleza ligada). Una vez analizado el comportamiento de estas unidades y clasificadas según estos criterios, deben incorporarse como lemas en los diccionarios aquellas cuyo uso se ha generalizado y, además, se debe dar cuenta de los cambios semánticos que estas suelen experimentar, es decir, cuando sufren procesos de banalización, mediante los cuales "se liberan del modelo etimológico que les dio nacimiento para pasar a depender del modelo funcional" (Alba de Diego, 1983: 18) que les permiten participar con otra significación en una segunda generación formativa. El diccionario debe ser, indudablemente, el que dé cuenta de estos cambios.

En definitiva, a partir del análisis de la composición en la historia de la lexicografía, esta investigación ha querido aportar una serie de propuestas para un mejor tratamiento lexicográfico, sobre todo, de aquellos aspectos más controvertidos en el seno de la teoría morfológica. Con ello, ha querido contribuir, en la medida de lo posible, a la poca atención que ha recibido la formación de palabras por composición desde el punto de vista de la práctica lexicográfica.

\section{BIBLIOGRAFÍA}

Adelstein, Andreína (1998): "Banalización de términos con formantes de origen grecolatino", en Red Iberoamericana de Terminología (ed.), V Simposio Iberoamericano de TerminologíaRiterm, México, Riterm, pp. 12-17. 
Alba de Diego, Vidal (1983): “Elementos prefijales o sufijales: ¿derivación o composición?", en Serta Philologica Fernando Lázaro Carreter, I, Madrid, Cátedra, pp. 17-21.

Alemany y Bolufer, José (1917): Diccionario de la Lengua Española, Barcelona, Ramón Sopena. Alemany y Bolufer, José (1920): Tratado de la formación de palabras en la lengua castellana, Madrid, Librería general de Victoriano Suárez.

Almela, Ramón (1999): La formación de palabras en español, Barcelona, Ariel.

Almela, Ramón (2003): “¿Unos compuestos demasiado "fronterizos”?”, en Ramón Almela, Dolores Anunciación Igualada, José María Jiménez y Agustín Vera (coords.), Homenaje al profesor Estanislao Ramón Trives, Murcia, Universidad de Murcia, pp. 87-102.

Alonso Ramos, Margarita (ed.) (2006): Diccionarios y fraseología (Anexos de la Revista de Lexicografía, 3), A Coruña, Servizo Publicacións Universidade da Coruña.

Alvar Ezquerra, Manuel (1993): La formación de palabras en español, Madrid, Arco/Libros.

Alvar, Manuel (2002): "El Diccionario de la Academia en sus prólogos", en De antiguos y nиevos diccionarios del español, Madrid, Arco/Libros, pp. 253-286.

Aut.: Real Academia Española (1726-1737 [1990]): Diccionario de autoridades, edición facsímil, Gredos, Madrid.

Bernal Gallén, Elisenda (2009): "Nuevos prefijos: implicaciones para la morfología y la lexicografía", en Maria Iliescu et al. (eds.), Actes du XXVe Congrès International de Linguistique et Philologie Romanes, VII, Tübingen, Max Niemeyer, pp. 361-373.

Buenafuentes de la Mata, Cristina (2006): "Estudio evolutivo de la composición culta a partir de procesos de gramaticalización y lexicalización”, en José Rodríguez Molina y Daniel M. Sáez de Rivera (coords.), Diacronía, lengua española y lingüística, Madrid, Síntesis, pp. 211-223.

Buenafuentes de la Mata, Cristina (2008): "Naturaleza de los adverbios y preposiciones que intervienen en la formación de palabras: entre la derivación y la composición", Moenia, 13, pp. 105-120.

Buenafuentes de la Mata, Cristina (2010): La composición sintagmática en español, San Millán de la Cogolla, Cilengua.

Buenafuentes de la Mata, Cristina (2012): "Composición y relaciones espaciales: procesos de gramaticalización y lexicalización”, en Elisenda Bernal, Carsten Sinner y Martina Emsel (eds.), Tiempo y espacio en la formación de palabras, Munich, Peniope, pp. 199-213.

Bustos Gisbert, Eugenio de (1986): La composición nominal en español, Salamanca, Universidad de Salamanca.

Cabré Castellví, María Teresa (1995): "Terminologia i diccionaris", en Josep Massot i Muntaner (coord.), Miscel-lània Germà Colón-4, Estudis de llengua i literatura catalanes, XXXI, Barcelona, Publicacions de l'Abadia de Montserrat, pp. 277-305.

Cabré Castellví, María Teresa (2002): "La derivació", en Joan Solà, Maria-Rosa Lloret, Manuel Pérez Saldanya y Joan Mascaró (eds.), Gramàtica del català contemporani, 1, Barcelona, Empúries, pp. 731-775.

Caluwe, Johan de y Johan Taeldeman (2003): "Morphology in dictionaries", en Piet van Sterkenburg (ed.), A Practical Guide to Lexicography, Amsterdam, John Benjamins, pp. 114-126.

CLAVE: Maldonado González, Concepción (dir.) (2002): CLAVE. Diccionario de uso del español actual, Madrid, Ediciones SM.

Corbin, Danielle y Pierre Corbin (1989): "Sélection et description des dérivés composés dans le dictionnaire monolingue", en Franz Joseph Hausmann et al. (eds.), Wörterbücher. An International Encyclopedia of Lexicography, Band 5.1, Berlin-New York, Walter de Gruyter, pp. 937-946.

Covarrubias, Sebastián de (1611): Tesoro de la lengua castellana o española, Madrid, Luis Sánchez.

Darmesteter, André (1874): Traité de la formation des mots composés, Paris, E. Buillon.

DEA: Seco, Manuel; Olimpia Andrés y Gabino Ramos (1999): Diccionario del español actual, Madrid, Aguilar. 
DECH: Corominas, Joan y José Antonio Pascual (1980-1991): Diccionario Crítico Etimológico Castellano e Hispánico, Madrid, Gredos.

Díaz Hormigo, María Tadea (2009): "La evolución del tratamiento de los elementos de formación de palabras en diccionarios generales: los denominados prefijos", en Teresa Bastardín, Manuel Rivas y José María García Martín (coords.), Estudios de historiografía lingüística, Universidad de Cádiz, Servicio de Publicaciones, pp. 167-188.

DIEC: Institut d'Estudis Catalans (2007): Diccionari de la llengua catalana, $2^{\mathrm{a}}$ ed, Barcelona, Edicions 62 y Enciclopèdia catalana.

Domínguez, Joaquín (1853): Diccionario Nacional o Gran Diccionario Clásico de la Lengua Española (1846-47), Madrid-París, Establecimiento de Mellado.

DPD: Real Academia Española (2005): Diccionario panhispánico de dudas, Madrid, Santillana.

DRAE (1832): Real Academia Española, Diccionario de la lengua castellana por la Real Academia Española. Séptima edición. Madrid, Imprenta Real.

DRAE (1869): Real Academia Española, Diccionario de la lengua castellana por la Real Academia Española. Undécima edición, Madrid, Imprenta de Don Manuel Rivadeneyra.

DRAE (1884): Real Academia Española, Diccionario de la lengua castellana por la Real Academia Española. Duodécima edición, Madrid, Imprenta de D. Gregorio Hernando.

DRAE (1899): Real Academia Española, Diccionario de la lengua castellana por la Real Academia Española. Décimatercia edición, Madrid, Imprenta de los Sres. Hernando y compañía.

DRAE (1927): Real Academia Española, Diccionario manual e ilustrado de la lengua española, Madrid, Espasa-Calpe.

DRAE (1970): Real Academia Española, Diccionario de la lengua española. Décimonovena edición, Madrid, Espasa-Calpe.

DRAE (2001): Real Academia Española, Diccionario de la lengua española, Madrid, EspasaCalpe, $22^{\mathrm{a}}$ edición.

DSLE: Gutiérrez Cuadrado, Juan (dir.) (1996): Diccionario Salamanca de la lengua española, Salamanca, Universidad de Salamanca.

DUE: Moliner, María (2007): Diccionario de uso del español, $3^{\mathrm{a}}$ ed., Madrid, Gredos.

DUEAE: Battaner Arias, M. ${ }^{a}$ Paz (dir.) (2002): Diccionario de uso del español de América y España, Barcelona, Spes (VOX).

García Platero, Juan Manuel (2000): "Presencia de las voces seudosufijadas en los diccionario del español”, en Stefan Ruhstaller y Josefina Prado Aragonés (eds.), Tendencias en la investigación lexicográfica del español. El diccionario como objeto de estudio lingüístico y didáctico, Huelva, Servicio de Publicaciones, Universidad de Huelva, pp. 425-432.

Gaspar y Roig (1853): Diccionario enciclopédico de la lengua española, con todas las vozes, frases, refranes y locuciones usadas en España y las Américas Españolas [...], tomo I, Madrid, Imprenta y Librería de Gaspar y Roig.

González Ollé, Fernando y Manuel Casado Velarde (1991): "Formación de palabras", en Günther Holtus, Michael Metzeltin y Christian Schmitt (eds.), Lexikon der Romanistischen Linguistik (LRL), VI, 1, Tübingen, Max Niemeyer Verlag, pp. 91-109.

González Pérez, Rosario (2002): "El tratamiento de las raíces sufijas y prefijas", en José Ignacio Pérez Pascual y Mar Campos Souto (eds.), Cuestiones de lexicografía, Lugo, Tris Tram, pp. 107-117.

Guerrero Ramos, Gloria y Fernando Pérez Lagos (2009): "La composición culta y la neología en la prensa escrita", Revista de Investigación Lingüística, 12, pp. 65-81.

Hanssen, Federico (1913): Gramática histórica de la lengua castellana, ed. facsímil, Buenos Aires, El Ateneo.

Lang, Merving F. (1992): Formación de palabras en español, Madrid, Cátedra.

Lázaro Mora, Fernando (1986): "Sobre la parasíntesis en español", Dicenda, 5, pp. 221-235.

Lorenzo, Emilio (1995): "La derivación nominal en español actual", Donaire, 4, pp. 35-41.

Malkiel, Yakob (1993): "El análisis genético de la formación de palabras", en Soledad Varela (ed.), La formación de palabras, Madrid, pp. 71-115. 
Martín García, Josefa (2000): "La morfología derivativa en la lexicografía española”, en Francisco José Ruiz de Mendoza (coord.), Panorama actual de la lingüística aplicada, II, Logroño, Mogar Linotype, pp. 1081-1088.

Menéndez Pidal, Ramón (1940): Manual de gramática histórica, Madrid, Espasa-Calpe.

Minghetto, David (1989): “¿Toro-robot o robot-toro? Compuestos con guión en prensa española", en Dieter Kremer (ed.), Actes du XVIII ${ }^{e}$ Congrès International de Linguistique et de Philologie Romanes, IV, Tübingen, Max Niemeyer Verlag, pp. 332-340.

NGLE: Real Academia Española y Asociación de Academias de la Lengua Española (2009): Nueva gramática de la lengua española, Madrid, Espasa Libros.

Ortografía (1999): Real Academia Española (1999): Ortografía de la lengua española, Madrid, Espasa-Calpe.

Ortografía (2010): Real Academia Española y Asociación de Academias de la Lengua Española (2010): Ortografía de la lengua española, Madrid, Espasa Libros.

Pena, Jesús (1994-1995): "Formación de palabras, gramática y diccionario", Revista de Lexicografía, 1, pp. 163-181.

Pena, Jesús (2002): “Morfología derivativa y diccionario", en Aleixandre Veiga, Miguel González Pereira y Montserrat Gómez Souto (eds.), Léxico y gramática, Lugo, Tris Tram, pp. 285-298.

Real Academia Española (1973): Esbozo de una nueva gramática de la lengua española, Madrid, Espasa-Calpe.

Rodríguez Navas y Manuel Carrasco (1918): Diccionario general y técnico hispano-americano, Madrid, Cultura Hispanoamericana.

Salvá, Vicente (1846): Nuevo diccionario de la lengua castellana, que comprende la última edición íntegra, muy rectificada y mejorada del publicado por la Academia Española, y unas veinte y seis mil voces, acepciones, frases y locuciones, entre ellas muchas americanas [...], Paris, Vicente Salvá.

Terreros y Pando, Esteban de (1786): Diccionario castellano con las voces de ciencias y artes y sus correspondientes en las tres lenguas francesa, latina e italiana [...], Madrid, Viuda de Ibarra.

Toro y Gómez, Miguel de (1901): Nuevo diccionario enciclopédico ilustrado de la lengua castellana, Paris-Madrid, Librería Armand Colin-Hernando y Cía.

Torres Martínez, Marta (2006): "Algunos apuntes sobre morfología derivativa en las primeras obras académicas: Diccionario de Autoridades (1726-1739) y Gramática de la lengua castellana (1771)", en Milka Villayandre (ed.), Actas del XXXV Simposio Internacional de la Sociedad Española de Lingüística, León, Universidad de León, pp. 1847-1868.

Torres Martínez, Marta (2008): "Tratamiento de los "elementos compositivos" en la lexicografía española académica y extraacadémica del siglo XX", en Dolores Azorín (dir.), El diccionario como puente entre las lenguas y culturas del mundo. Actas del II Congreso Internacional de Lexicografía Hispánica, Alicante, Biblioteca Virtual Miguel de Cervantes, pp. 393-401.

Val Álvaro, Francisco de (1999): "La composición”, en Ignacio Bosque y Violeta Demonte (eds.), Gramática descriptiva de la lengua española, III, Madrid, Espasa-Calpe, pp. 4757-4841.

Varela, Soledad (1992): Fundamentos de morfología, Madrid, Síntesis.

Varela, Soledad y Josefa Martín García (1999): "La prefijación”, en Ignacio Bosque y Violeta Demonte (dirs.), Gramática descriptiva de la lengua española, III, Madrid, Espasa-Calpe, pp. 4993-5038.

Zerolo, Elías (1895): Diccionario enciclopédico de la lengua castellana, Paris, Garnier hermanos.

Fecha de recepción: 15 de septiembre de 2011

Fecha de aceptación: 7 de marzo de 2012 